NBER WORKING PAPER SERIES

\title{
MANUFACTURER LIABILITY FOR HARMS CAUSED BY CONSUMERS TO OTHERS
}

\author{
Bruce Hay \\ Kathryn E. Spier \\ Working Paper 10972 \\ http://www.nber.org/papers/w10972
NATIONAL BUREAU OF ECONOMIC RESEARCH
1050 Massachusetts Avenue
Cambridge, MA 02138
December 2004

The authors are from the Harvard Law School and the Kellogg School of Management and NBER, respectively. The authors thank Rick Brooks, Howard Chang, Jim Dana, Andy Daughety, Xinyu Hua, Mitch Polinsky, Jennifer Reinganum, Scott Schaefer, seminar audiences at Kellogg and the NBER, and especially Steve Shavell, Tim Besley, and the referees for helpful comments and suggestions. The second author thanks the Searle Fund for financial support. The views expressed herein are those of the author(s) and do not necessarily reflect the views of the National Bureau of Economic Research.

(C) 2004 by Bruce Hay and Kathryn E. Spier. All rights reserved. Short sections of text, not to exceed two paragraphs, may be quoted without explicit permission provided that full credit, including $(\odot$ notice, is given to the source. 
Manufacturer Liability for Harms Caused by Consumers to Others

Bruce Hay and Kathryn E. Spier

NBER Working Paper No. 10972

December 2004

JEL No. K13, D62

\begin{abstract}
$\underline{\text { ABSTRACT }}$
Should the manufacturer of a product be held legally responsible when a consumer, while using the product, harms someone else? We show that if consumers have deep pockets then manufacturer liability is not economically efficient. It is more efficient for the consumers themselves to bear responsibility for the harms that they cause. If homogeneous consumers have limited assets, then the most efficient rule is "residual-manufacturer liability" where the manufacturer pays the shortfall in damages not paid by the consumer. Residual-manufacturer liability distorts the market quantity when consumers' willingness to pay is correlated with their propensity to cause harm. It distorts product safety when consumers differ in their wealth levels. In both cases, consumer-only liability may be more efficient.

Bruce Hay Harvard Law School

Griswold Hall 401

1563 Massachusetts Avenue

Cambridge, MA 02138

hay@law.harvard.edu

Kathryn E. Spier

Kellogg School of Management

Northwestern University

2001 Sheridan Road

Evanston, IL 60208

and NBER

k-spier@kellogg.northwestern.edu
\end{abstract}




\section{Introduction}

Should the manufacturer of a product be held legally responsible when a consumer, while using the product, harms someone else? Manufacturers might be held liable for accidental harms caused by the consumer, such as when a lawnmower flings a stone that hits a neighbor in the eye or when a driver of a car hits a pedestrian. ${ }^{2}$ Manufacturers might also be held liable if the consumer intentionally caused harm, for example when a gun is used to commit murder. Indeed, recently many lawsuits have been brought recently against firearms manufacturers for the deaths and injuries caused by criminals who use guns. Although such lawsuits have generally been unsuccessful, ${ }^{3}$ these issues remain hotly discussed in the legal and political arenas. $^{4}$

We consider a model of a dangerous product supplied by a perfectly competitive market. The product's use has some tendency to harm others -- either accidentally or intentionally -- and both the manufacturers and the consumers can take actions to reduce the likelihood of the harm. For example, gun owners can take greater care while handling and storing their guns to avoid accidental shootings and can refrain from committing crimes; likewise, gun manufacturers can make investments in safety features such as mechanical gun locks (reducing the likelihood that a

\footnotetext{
${ }^{2}$ See Dugan v. Sears, Roebuck \& Co., 447 N.E.2d 1055 (Ill. App. 1983) (lawnmower) and Houvenagle v. Wright, 340 N.W.2d 783 (Ia. App. 1983) (automobile). Lawsuits involving other products such as alchohol, pesticides, cigarette lighters, and computer games abound.

${ }^{3}$ Exceptions involve situations where the consumer accidentally injured someone as a result of a product malfunction. If a car's brakes fail, for example, the pedestrian may be able to recover from the manufacturer provided that the brake failure is not the consumer's fault. However, if the product functioned as it was designed to, or if the consumer deliberately inflicted the injury, courts have traditionally refused to hold the manufacturer liable.

${ }^{4}$ A number of lawsuits are pending in federal and state courts in which the plaintiffs seek to relax or bypass the traditional rule immunizing manufacturers from deliberately inflicted harms. State and federal legislatures have responded by attempting to codify the manufacturers' immunity from liability. For example, two bills in Congress, H.R. 1036 and S. 696, would "prohibit civil liability actions from being brought or continued against manufacturers, distributors, dealers or importers of firearms or ammunition for damages resulting from the misuse of their products by others." The former bill has made it through the U.S. House of Representatives while the latter is pending in the U.S. Senate.
} 
child inadvertently shoots a sibling) or can refrain from producing highly lethal products, such as armor-piercing bullets.

We show that consumer liability is more efficient than manufacturer liability when consumers have deep pockets and can pay for the harms that they cause; solvent consumers fully internalize the social risks associated with their product use. This has three desirable effects. First, consumers take the optimal degree of care when using dangerous products. Second, they demand optimal safety features in the products that they buy. Third, the equilibrium market quantity is efficient because the market price plus the consumer's expected liability reflects the true social cost of the dangerous product. ${ }^{5}$

On the other hand, manufacturer liability may be more efficient when consumers lack the financial resources to pay for the harms that they cause. In a representative-consumer setting, we show that it is more efficient for the consumer to bear primary responsibility for the damages while manufacturers are held responsible for the shortfall not covered by the consumer. We call this rule "residual-manufacturer liability." Although consumers take inadequate precautions when using risky products, ${ }^{6}$ this rule gives manufacturers the correct incentive to design and produce safer products and insures that the market price reflects the manufacturers' expected future liability, leading to the efficient market quantity. ${ }^{7}$

Importantly, we show that residual-manufacturer liability may distort market outcomes when consumers are heterogeneous. Residual-manufacturer liability leads to quantity distortions, for example, when the consumers' elasticity of demand is systematically correlated with the social harm that they cause. If safe consumers are more price sensitive than their

\footnotetext{
${ }^{5}$ See Hamada (1976). This may not be true if consumers misperceive risks (Spence, 1977).

${ }^{6}$ Shavell (1986) formalizes the so-called "judgment-proof problem."

${ }^{7}$ Shavell (1980) showed that the higher price leads to a more efficient market quantity but did not discuss residual-manufacturer liability or the heterogeneity issues discussed here.
} 
harmful counterparts, then residual-manufacturer liability may depress the market quantity so much that society as a whole is better off imposing liability on the consumers alone. ${ }^{8}$ Residualmanufacturer liability may also lead to quality distortions. If consumers have private information about their heterogeneous financial assets, for example, then the solvent consumers purchase excessively safe products in equilibrium. Again, it may be more efficient to impose liability on the consumers alone than to hold manufacturers liable.

The issues raised here are distinct from those in the large literature that focuses on product injuries to consumers themselves. Simply put, product injuries to consumers are largely internalized in well-functioning markets (Hamada, 1976; Landes and Posner, 1985 and 1987). ${ }^{9}$ Even without manufacturer liability imposed by law, consumers would be willing to pay a premium for safer products that reduce their personal risk and to use risky products prudently. Consequently, the economic arguments for products liability for consumer injuries have focused on situations involving transactions costs and market imperfections. Manufacturer liability for consumer injuries may be efficient, for example, when consumers misperceive product risks (Spence, 1977; Epple and Raviv, 1978; Polinsky and Rogerson, 1983) or when manufacturers have private information about the safety of their products or take unobservable actions that affect product safety (Daughety and Reinganum, 1995 and 1997). ${ }^{10}$

Section 2 highlights the optimality of residual-manufacturer liability in a representative

\footnotetext{
${ }^{8}$ Previous legal commentators (Note, 1995a and 1995b) have argued in favor of manufacturer liability for gun misuse. With the exception of Hay's (1999) informal analysis, the quantity distortion issue has been unaddressed in the literature.

${ }^{9}$ Consumers and manufacturers jointly absorb the costs of injuries (with the allocation depending upon the contract struck between them) and therefore have a joint incentive to take optimal precautions. Early descriptive work includes Calabresi (1961) and McKean (1970).

${ }^{10}$ The issues here are reminiscent of vicarious liability (Sykes, 1998; Mattiacci and Parisi, 2002), holding employers liable for the negligence of their employees, for example. Our problem differs in that employers exert some supervision over their employees and can discharge unsatisfactory employees. Manufacturers, on the other hand, typically cannot control how their products are used after the sale.
} 
consumer framework. Section 3 shows that residual-manufacturer liability can distort the market quantity in an example where consumers have heterogeneous demand curves and harm propensities. Section 4 shows that residual-manufacturer liability can distort product safety in an example where consumers are privately informed about their wealth levels. Section 5 concludes. All proofs are given in the appendix.

\section{The Basic Framework}

We begin with the case of a representative consumer purchasing a harmful product from a perfectly competitive market. The probability that a single unit of the good will cause an injury is $\pi(x, y)$, where $x \geq 0$ is the manufacturer's investments in product safety and $y \geq 0$ is the consumer's precaution level. Product safety is perfectly observable to the consumer at the time that he makes his purchase decisions. The manufacturers have identical constant-returns-to-scale production technologies with marginal production cost $x$ (we normalize the other production costs to zero). We assume that $\pi(x, y)$ is decreasing in each argument, is strictly convex, and that $\operatorname{Lim}_{x \rightarrow 0} \pi_{1}(x, y)=-\infty$ and $\operatorname{Lim}_{y \rightarrow 0} \pi_{2}(x, y)=-\infty .{ }^{11}$ This last condition implies that the marginal return from the first dollar of investment is arbitrarily large.

When injured, the third parties suffer damages $d>0$. Consumers are said to be insolvent or "judgment-proof" when their future assets, $w$, are insufficient to cover $d .^{12}$ In contrast to the consumers, manufacturers are assumed to have deep pockets. The representative consumer receives a marginal benefit $P(q)$ from consuming the $q^{\text {th }}$ unit of the good. This is the

\footnotetext{
${ }^{11} \pi_{i}(x, y)$ is the derivative with respect to argument $i=x, y$.

${ }^{12}$ Note that the price that the consumers pay ex ante is not deducted from their future wealth. This is quite realistic when injuries are low probability events. Similar results would be obtained if consumers have deep pockets but there is a low probability of being held responsible for the damages.
} 
inverse demand curve net of any liability concerns.

Social welfare is given by: ${ }^{13}$

$$
S(x, y, q)=\int_{0}^{q}[P(z)-\pi(x, y) d-x-y] d z .
$$

The first-best market outcome, $x^{*}, y^{*}$, and $q^{*}$, are the values that maximize this expression. The competitive market chooses these values privately, of course, in the shadow of future liability. We consider the general class of strict liability rules, $\left\{\delta^{c}, \delta^{m}\right\}$, that allocates damages $\delta^{c} \leq w$ to the consumer and $\delta^{m}$ to the manufacturer. ${ }^{14}$ We also highlight two specific rules. With consumer-only liability the consumer pays for third-party damages to the point where his or her financial assets are exhausted, $\delta^{c}=\min \{d, w\}$ and $\delta^{m}=0$. With residual-manufacturer liability the manufacturer is held legally liable for the shortfall in damages, $\delta^{c}=\min \{d, w\}$ and $\delta^{m}=d-\min \{d, w\}$.

Manufacturers compete by offering price-safety pairs to attract the representative consumer. The manufacturers are the "leaders" (so to speak) choosing price and product safely first while the representative consumer is a "follower," subsequently choosing his quantity and precautions. In equilibrium, consumer surplus is maximized subject to three constraints:

$$
\underset{\{p, x\}}{\operatorname{Max}} \int_{0}^{q}\left[P(z)-\pi(x, y) \delta^{c}-y-p\right] d z
$$

\footnotetext{
${ }^{13}$ While our notation naturally reflects accidental harms the framework is also valid for intentional harms, including crimes. Even criminals can take actions to reduce unnecessary losses (collateral property damage, injuries and deaths) while engaging in criminal activities and can spend effort searching for non-criminal alternatives (getting a job, going to school). Criminals may also borrow or steal guns from consumers; liability gives consumers the incentive to safeguard their firearms. The proper treatment of the criminal's utility in the social welfare function is debatable, of course, and not addressed here. ${ }^{14}$ Note that this class does not include rules where the liability depends on the precautions taken by the manufacturer and the consumer. Negligence rules are discussed in the conclusion. We are implicitly assuming that only one injury can occur for a given consumer. This is justified if injuries occur with a random arrival rate and economic activity ceases after the first one.
} 


$$
\begin{array}{ll}
\text { s.t. } & -\pi_{2}(x, y) \delta^{c}-1=0 \\
& P(q)=\pi(x, y) \delta^{c}+y+p \\
& p \geq x+\pi(x, y) \delta^{m} .
\end{array}
$$

The first constraint reflects that the consumer chooses his precautions, $y$, to minimize the expected private cost associated with product use. The second constraint says that the consumer consumes to the point where his marginal value of consumption is exactly offset by his expected unit cost. The final inequality constrains manufacturers to earn non-negative profits.

Proposition 1: When the representative consumer is fully solvent then consumer-only liability achieves the first-best market outcome.

When the representative consumer pays in full for the damages that he causes he will invest optimally in precautions to avoid harming others. Furthermore, the consumer is willing to pay a premium to manufacturers for optimally safe products and the competitive market delivers exactly what he wants. Finally, the consumer purchases the socially optimal quantity because his unit cost reflects the full social cost: the sum of the marginal cost of production, the cost to the consumer of taking precautions, and the expected damages to third parties.

Next, suppose that consumers are insolvent. The first-best outcome is clearly not achieved with consumer-only liability. Since the consumer bears less than full responsibility for the harms he causes he will take too few precautions to avoid harming others. Since products are designed with only the consumer's preferences in mind, manufacturers will underinvest in safety features. Finally, the consumer purchases too much of the product as his unit cost of consumption falls short of the true social cost. 
Proposition 2: When the representative consumer has limited financial assets then residualmanufacturer liability is optimal within the class of strict liability rules.

It is unavoidable that consumer precautions fall short of their first-best levels, but putting primary responsibility on the consumer at least pushes his precautions in the right direction. Putting residual responsibility on the manufacturer leads the market price to reflect the manufacturer's share of the expected future damages in addition to the production cost. Consequently, the consumer's unit cost will fully reflect the social cost of the risky product and so the market quantity is socially optimal. Finally, this rule leads the manufacturers to invest efficienty in product safety. Intuitively, this happens because the manufacturer and the consumer together are jointly responsible for the full social harm to third parties.

Other policy instruments, such as taxation and mandatory insurance policies for consumers, will perform well on some -- but not all -- dimensions. These alternative instruments, if carefully chosen, will achieve the efficient market quantity. They will not by themselves get consumers to take additional care or manufacturers to implement socially desirable safety features, however. Taxes would need to be coupled with other instruments -regulations or negligence-based liability rules perhaps -- in order to mimic all of the benefits of residual-manufacturer liability.

The basic model can be extended in number of ways without changing the basic conclusion. The results hold in situations where consumers themselves are harmed in addition to the third parties. ${ }^{15}$ They also hold when the harms to others stochastic rather than deterministic.

\footnotetext{
${ }^{15}$ The working paper version of this paper, available on SSRN, includes consumer harm. This feature has been dropped to streamline the exposition.
} 
The framework could be easily extended to include non-financial sanctions, such as criminal penalties for careless or malicious product use. While useful, these supplements would not generally achieve the first-best: the combined threat of civil and criminal liability is generally insufficient to induce efficient behavior. Finally, the framework could be extended to situations where product safety features interfere with product use, diluting the value that the consumer derives from the product. ${ }^{16}$

The optimality of residual-manufacturer liability is maintained with some forms of consumer heterogeneity. Importantly, the representative consumer's inverse demand curve $P(q)$ can be easily reinterpreted as representing a continuum of consumers who differ in the value they place on consuming a single unit of the good. Residual-manufacturer liability is socially efficient so long as the different consumer types all have the same wealth level and the same propensity to cause social harm, $h$. The next two sections highlight why residual-manufacturer liability may be undesirable when these other forms of heterogeneity are introduced.

\section{Quantity Distortions: Heterogeneous Harm Levels}

This section allows consumers to differ from one another in both their price sensitivities and in the social harms that they cause to third parties. We show that residual-manufacturer liability can distort the market quantity when these parameters are correlated in the consumer population. Indeed, residual-manufacturer liability may create such large distortions in the market quantity that it would be more efficient to have no manufacturer liability at all.

We make two simplifying assumptions here in order to focus attention on quantity

\footnotetext{
${ }^{16}$ The framework could be extended to consider imperfect competition. Residual-manufacturer liability would clearly change market prices in this case, too, although the change may not be efficient. Additional work on these issues is needed.
} 
distortions. First, neither the manufacturers nor the consumers can affect the probability of injuries to others, $x=y=0$. Second, consumers are assumed to be totally insolvent following these injuries, $w=0$. We extend the earlier framework to allow for two types of customers, $i=$ $H, L$. We will refer to these two types as the "harmful group" and the "safe group," respectively. The expected social harm of a single unit of the product in the hands of a type $i$ consumer is $\Delta_{i}=\pi_{i} d_{i}$ and we assume that $\Delta_{H}>\Delta_{L}>0$. The inverse demand curve of type $i$ consumers is $P_{i}(q)$ and the corresponding demand curve is $D_{i}(p)$. We assume that it is impossible for manufacturers to distinguish between the two types of customers and therefore cannot engage in price discrimination.

An all-knowing social planner would, of course, set different prices for the two groups of consumers, but this is infeasible given our assumptions. The appropriate benchmark has the social planner setting a single price for both groups. This second-best price must reflect the social harm associated with the sale of one additional unit, or the marginal social harm: ${ }^{17}$

$$
p^{*}=\frac{\Delta_{H} D_{H}^{\prime}\left(p^{*}\right)+\Delta_{L} D_{L}^{\prime}\left(p^{*}\right)}{D_{H}^{\prime}\left(p^{*}\right)+D_{L}^{\prime}\left(p^{*}\right)} .
$$

With residual-manufacturer liability, the competitive equilibrium price reflects the manufacturer's expected liability associated with a sale of one unit, or the average social harm: ${ }^{18}$

$$
p^{R}=\frac{\Delta_{H} D_{H}\left(p^{R}\right)+\Delta_{L} D_{L}\left(p^{R}\right)}{D_{H}\left(p^{R}\right)+D_{L}\left(p^{R}\right)} .
$$

When the average and marginal harms values diverge, residual-manufacturer liability distorts the

17 Suppose that price falls so that exactly one more unit is sold. With probability $D_{H}^{\prime}\left(p^{*}\right) /\left[D_{H}^{\prime}\left(p^{*}\right)+D_{L}^{\prime}\left(p^{*}\right)\right]$ the additional unit is sold to a type $\mathrm{H}$ consumer, and with probability $D_{L}^{\prime}\left(p^{*}\right) /\left[D_{H}^{\prime}\left(p^{*}\right)+D_{L}^{\prime}\left(p^{*}\right)\right]$ it is sold to a consumer of type L. Multiplying these probabilities by the associated social harms, $\Delta_{H}$ and $\Delta_{L}$ gives the expression.

${ }^{18}$ The total social harm $\Delta_{H} D_{H}(p)+\Delta_{L} D_{L}(p)$ divided by the total quantity $D_{H}(p)+D_{L}(p)$. 
equilibrium market quantity.

Proposition 3: If the harmful consumer group has a more elastic demand curve than the safe consumer group then the market quantity under residual-manufacturer liability is higher than the second-best quantity. If the harmful consumer group has a less elastic demand curve then the equilibrium market quantity is lower than the second-best quantity.

Suppose that the harmful consumer group has a more elastic demand curve than the safe consumer group. When the market price rises, the percentage of harmful consumers who leave the market is larger than the percentage of safe consumers who leave. It follows that the marginal purchaser (i.e. the consumer who is indifferent between buying the gun and not buying the gun at the going price) is more likely to be a harmful consumer than the average purchaser in the market. Since residual-manufacturer liability effectively "taxes" manufacturers for the average social harm the market price will be inefficiently low and the market quantity inefficiently high. Conversely, when the harmful consumer group has a less elastic demand curve then when the market price rises the safe consumers leave the market at a higher rate than harmful consumers. The marginal purchaser is more likely to be a safe type than the average purchaser. In this case, manufacturers are "over-taxed" with residual-manufacturer liability.

Proposition 4: When the harmful consumer group has a more elastic demand than the safe consumer group then residual-manufacturer liability is more efficient than consumer-only liability. When the harmful consumer group has a less elastic demand then residualmanufacturer liability may be more or less efficient than consumer-only liability. 
Residual-manufacturer liability can have disastrous consequences when the harmful consumers are less price sensitive than their safe counterparts. The consumers who cause the least social harm are the first to drop out of the market when the market price rises while the consumers who cause the most social harm are the ones more likely to remain. Consumer-only liability may be more efficient because it keeps the safe consumers in the market.

This may be seen in a simple numerical example. Suppose there is a population of consumers, each of whom demands at most one unit of the good. Each unit costs $\$ 10$ to produce. Suppose that $99 \%$ of the population causes no harm but $1 \%$ causes harm of $\$ 300$. Furthermore, suppose that the safe consumers value the product less than the harmful consumers: $v_{L}=\$ 12.99$ and $v_{H}=\$ 310.01$. Both types of consumer "should" purchase the product in this example: $99 \%$ of the population creates a surplus of $\$ 2.99$ while $1 \%$ of the population creates a social value of a penny. With consumer-only liability, competition drives the price down to $\mathrm{p}=\$ 10$, the marginal cost of production. The socially optimal outcome is obtained: all consumers -- safe and harmful alike -- buy the product. Now consider residualmanufacturer liability. If both types of consumer purchased the product the price would be $p=$ $\$ 13$, above safe consumers' valuation of $\$ 12.99$. So the safe consumers would be driven from the market and the price would subsequently rise to $\mathrm{p}=\$ 310$, the marginal cost, $\$ 10$, plus the expected social harm caused by harmful types, $\$ 300$. Only the harmful $1 \%$ of the population purchases the product, and, for these harmful consumers, the "social surplus" is just a penny. Social welfare has obviously fallen. ${ }^{19}$

Proposition 5: Suppose that the variance in the population's harms grows while holding the

${ }^{19}$ If the social surplus for the unsafe consumers were negative then the market would disappear. 
average harm constant at price $p^{R}$. If the harmful consumer group has a less elastic demand curve than the safe consumer group then consumer-only liability becomes more efficient relative to residual-manufacturer liability.

When the two consumer types are equally harmful, residual-manufacturer liability clearly dominates consumer-only liability on efficiency grounds (indeed, it achieves the second-best market outcome; see Proposition 3). When the variance in harms grows, however, then residualmanufacturer liability diverges from the second-best and becomes relatively less efficient. The proposition holds social welfare under residual-manufacturer liability fixed (by holding average harm constant at $p^{R}$ ) and performs the comparative static on consumer-only liability. Alternatively, one could hold social welfare fixed under consumer-only liability and show that residual-manufacturer liability becomes relatively less efficient although this is less straightforward to prove.

Our analysis has restricted attention to two specific liability rules: residual-manufacturer and consumer-only liability. Social welfare would of course be higher if the social planner could fine-tune the rule. Damage multipliers would be valuable supplementary instrument to residualmanufacturer liability, for example. The optimal multiplier would be less than one when consumers with less elastic demands cause more social harm, effectively lowering the manufacturers' liability to reflect marginal harm. Similarly, it would be greater than one when the less elastic consumers cause less social harm. Alternatively, the social planner could impose a direct tax on the manufacturers reflecting the marginal social harm of the activity. These policies would of course require that the court understand a host of market characteristics including the nature of demand curves, harm levels, and correlations, etc. They would also 
compromise the positive impact manufacturer liability has on product design.

\section{Quality Distortions: Heterogeneous Financial Assets}

This section introduces a second kind of consumer heterogeneity: heterogeneous financial assets. Proportion $\theta$ of the consumer population, the "type 0 " consumers, are completely insolvent following an injury $\left(w_{0}=0\right)$. Proportion $1-\theta$ of the consumer population, the "type $1 "$ consumers, are fully solvent $\left(w_{1}>d\right)$. Finally, we assume that the probability of harm is additively separable in manufacturer and consumer precautions, $\pi_{12}(x, y)=0 .{ }^{20} \mathrm{We}$ will characterize incentive-compatible pairs of product offerings, $\left\{p_{0}, x_{0}\right\}$ and $\left\{p_{1}, x_{1}\right\}$, where the insolvent consumers select the former and the solvent consumers select the latter. The pair of product offerings is a competitive equilibrium if no manufacturer can earn positive profits by deviating to a different price-safety combination. Finally, the equilibrium is said to be pooling when $\left\{p_{0}, x_{0}\right\}=\left\{p_{1}, x_{1}\right\}$ and separating otherwise.

As before, we focus on two basic liability rules. With consumer-only liability the damages are paid by the consumer when he is fully solvent and go uncompensated otherwise, $\left\{\delta_{1}^{c}, \delta_{1}^{m}\right\}=\{d, 0\}$ and $\left\{\delta_{0}^{c}, \delta_{0}^{m}\right\}=\{0,0\}$. With residual-manufacturer liability the damages are paid by the consumer when he is fully solvent but are paid by the manufacturer if the consumer is insolvent, $\left\{\delta_{1}^{c}, \delta_{1}^{m}\right\}=\{d, 0\}$ and $\left\{\delta_{0}^{c}, \delta_{0}^{m}\right\}=\{0, d\}$.

Proposition 6: With consumer-only liability, the solvent consumers' purchasing decisions and precautions are at their first-best levels. The insolvent consumers purchase unsafe products, take

\footnotetext{
${ }^{20}$ This implies that a consumer's choice of precautions is independent of product safety features.
} 
too few precautions, and consume too much.

As in Section 2, the insolvent customers do not care enough about safety and the competitive market gives them exactly what they want: a cheap and relatively dangerous product. They subsequently put in too little care to avoid harming others and overconsume the product. The fully solvent consumers, on the other hand, are held personally accountable for any third-party damages and therefore demand safer products from the manufacturers and use them prudently. In short, the competitive market supplies the solvent consumers "efficiently."

Lemma 7: Suppose the consumers' types are observable and price discrimination is feasible. With residual-manufacturer liability, all consumers purchase optimally safe products. The price paid by the solvent consumers reflects marginal production costs only while the insolvent consumers pay a premium that reflects the manufacturer's future liability. Conditional on product safety and consumer precautions, efficient market quantities are obtained.

This full-information benchmark may be understood intuitively. Solvent consumers demand optimally safe products because primary liability forces them to internalize the social harms they cause. Insolvent consumers do not personally internalize the harm, but the manufacturers supplying them are forced to internalize the harm through residual-manufacturer liability (as in Section 2). The solvent consumers pay ex post for the harm that they cause while the insolvent consumers pay ex ante through a higher market price.

This benchmark is not sustainable when the consumer are privately informed. Since the insolvent consumers pay a higher price than their solvent counterparts the insolvent consumers 
would obviously pretend to be solvent in order to secure the lower price. In other words, the fullinformation benchmark is not incentive compatible.

Proposition 8: Suppose that consumers' types are private information. With residualmanufacturer liability a pooling equilibrium does not exist. There does exist a unique separating equilibrium when the proportion of insolvent consumers, is not too small. The fully solvent consumers purchase excessively safe products and the insolvent consumers purchase optimally safe products. Conditional on the precaution levels, the efficient market quantities are obtained.

A detailed proof is given in the appendix, but the main ideas may be understood intuitively. If a pooling equilibrium did exist, the market price would have to be inflated to reflect the manufacturers' liability associated with the insolvent consumers. Consumers who are solvent face primary liability for third-party harm and therefore place greater weight on product safety than their insolvent counterparts. A clever manufacturer could skim off these safetysensitive consumers in the following way: offer a safer product at a price that only the solvent consumers would prefer. The manufacturer would avoid future liability himself and earn a positive profits.

This intuition is applicable in understanding the separating equilibrium as well. The market supplies a product with optimal built-in safety features to the insolvent consumers who pay for manufacturers' future liability up front through an inflated price. If the solvent consumers purchased this product, too, they would effectively have to pay twice for liability: once up front through the market price and then later on when a third party suffers damages. But the competitive market supplies the solvent consumers with a very different product -- a safer 
product at a higher price. This ultra-safe product is priced "fairly" -- the solvent consumers are only paying the manufacturing costs and so their purchase decisions are efficient given the safety measures. -- but the safety measures themselves are inefficiently high. When $\theta$, the proportion of insolvent consumers, is small then a competitive equilibrium fails to exist. The reason is simple: a clever manufacturer could profitably deviate from the separating equilibrium and offer a product with socially optimal safety features and a relatively low price that both consumer types would prefer.

This Proposition is analogous to Rothschild and Stiglitz's (1976) famous result that competitive insurance markets may have no equilibrium. Many authors have suggested changes to Rothchild and Stiglitz's timing to restore the existence of equilibrium. Riley (1979) proposed a dynamic adjustment process where firms could modify their product offerings in light of a deviation. The separating equilibrium described above is a so-called "Reactive Equilibrium" when $\theta$ is low as well. The idea behind this is that if a deviator did indeed make an offer that both types of consumer preferred, then another firm could react to this deviation and skim off the solvent consumers. ${ }^{21}$ (A similar logic was used to break the pooling equilibrium.)

Proposition 9: If the proportion of insolvent consumers is above a cutoff then the separating outcome with residual-manufacturer liability is more efficient than the equilibrium with consumer-only liability. If the proportion of insolvent consumers is below the cutoff then consumer-only liability is more efficient.

\footnotetext{
${ }^{21}$ The robustness of the separating equilibrium for low $\theta$ is sensitive to the particular dynamic process, however. Indeed, Wilson (1977) restored the existence of a pooling equilibrium in Rothschild-Stiglitz by allowing the non-deviating firms to withdraw, but not modify, their offers in light of a deviation. These extensions, and other refinements, are surveyed in Riley (2001).
} 
From Proposition 6, consumer-only liability achieves the first-best outcome for solvent types while the insolvent types over-consume unsafe products and take too little care while using them. Residual-manufacturer liability, on the other hand, distorts the product safety supplied to the solvent customers in the separating equilibrium (Proposition 8). It follows that consumeronly liability is more efficient when there are sufficiently many solvent consumers in the population but not when the population is dominated by insolvent consumers.

\section{Conclusion}

There are sound economic reasons to hold manufacturers liable for the injuries that their products cause to non-consumers. Since consumers typically cannot be held responsible for $100 \%$ of the harms that they cause, placing liability on consumers alone will lead to the overconsumption of products with inadequate safety features. In a representative-consumer framework, the most efficient strict liability rule holds the consumer liable for third-party damages up to the point that their financial assets allow, and then holds the manufacturer liable for the shortfall in damages. ${ }^{22}$ However, when consumers are heterogeneous, residualmanufacturer liability can lead to undesirable distortions in the market quantities and product safety features.

The formal analysis in this paper ignored the costs of the legal system and assumed that victims were automatically compensated for their losses. Holding manufacturers liable would only make practical sense if the shortfall in damages not paid by consumers (and the associated benefit of residual-manufacturer liability) was large enough to justify the added expense and transactions costs associated with the litigation process. Additional problems would arise if

\footnotetext{
${ }^{22}$ The asymmetry in the treatment comes from the assumption that consumers observe product attributes at the time of purchase but manufacturers cannot observe or control consumer care.
} 
overly-sympathetic juries grant astronomical jury awards, chilling the economic activity.

Taxes may be a viable alternative to residual-manufacturer liability. ${ }^{23}$ The optimal tax, which would reflect the marginal social harm, could be imposed on either the manufacturers or the consumers. Although taxation may have lower transactions costs than residual-manufacturer liability, it has several important drawbacks. First, the planner would require both the time and the ability to fine-tune the taxes on a market-by-market basis. Second, a tax by itself would provide inadequate incentives for manufacturers to design safer products. A negligence rule that holds manufacturers liable if their safety features fall short of acceptable levels -- or regulations geared at product safety directly -- may prove useful supplements to taxation. Note, however, that liability has the advantage of putting responsibility for safety in the hands of experts. Manufacturers are likely to be better informed about the feasibility of product modifications than regulators.

Forcing consumers to purchase insurance policies when they own dangerous products is another possibility. This may suffer from the same problems as residual-manufacturer liability. If insurance providers cannot discriminate among the different types of consumers then the competitive insurance premiums would reflect the average rather than the marginal harm and the market quantity would be distorted. Furthermore, in the absence of manufacturer liability and other regulations product safety regulations, manufacturers would have insufficient incentives to produce safer products. $^{24}$ In this way, mandatory insurance has the same problems as taxation.

The results of this paper raise the natural question -- and concern -- about where the chain of corporate responsibility should end. The model assumed a single manufacturer, but harmful activities will often involve multiple products and multiple suppliers. Guns, for example, are

\footnotetext{
${ }^{23}$ See Carlton and Loury, 1980 and Hamilton, 1998, for discussions of Pigouvian taxation and liability.

${ }^{24}$ Indeed, one can interpret manufacturer liability as bundling the product with an insurance policy.
} 
especially dangerous when they are loaded with bullets. Should the ammunition manufacturer be held liable for deaths and injuries as well? Timothy McVeigh created the bomb that destroyed the Oklahoma City Federal Building by loading a mixture of fertilizer with diesel fuel -purchased at a Conoco service station -- into a rented Ryder truck. Should the fertilizer manufacturer, Conoco and Ryder all be held responsible for the 168 lives that were lost? ${ }^{25}$ These issues remain fruitful for further research.

\section{References}

Calabresi, G., "Some Thoughts on Risk Distribution and the Law of Torts," Yale Law Journal, Vol. 70 (4), 1961, pp. 499-553.

Carlton, Dennis W. and Glenn Loury, "The Limitations of Pigouvian Taxes as a Long-Run Remedy for Externalitites," Quarterly Journal of Economics, Vol. 95(3), 1980, pp. 559-566.

Andrew F. Daughety and Jennifer F. Reinganum, "Everybody Out of the Pool: Products Liability, Punitive Damages, and Competition," Journal of Law, Economics, and Organization, Vol. 13 (2), 1997, pp. 410-432.

Andrew F. Daughety and Jennifer F. Reinganum, "Product Safety: Liability, R\&D, and Signaling," American Economic Review, Vol. 85(5), 1995, pp.1187-1206.

Epple, Dennis and Artur Raviv, "Product Safety: Liability Rules, Market Structure, and Imperfect Information," American Economic Review, Vol. 68 (1), 1978, pp. 80-95.

Hamada, Koichi. "Liability Rules and Income Distribution in Product Liability," American Economic Review, Vol. 66 (1), 1976, pp. 228-234.

Hamilton, Stephen F., "Taxation, Fines, and Producer Liability Rules: Efficiency and Market Structure Implications," Southern Economic Journal, Vol. 65 (1), 1998, pp. 140-150.

Hay, Bruce, "Manufacturer Liability to Nonconsumers." Harvard Law School Mimeo, 1999.

Landes, William, and Richard Posner, "A Positive Economic Analysis of Products Liability," Journal of Legal Studies, Vol 14(3), 1985, pp. 535-567.

${ }^{25}$ See Gaines-Tabb v. ICI Explosives, USA, Inc., 160 F.3d 613 (10th Cir. 1998) for a case against fertilizer manufacturers. 
Landes, William, and Richard Posner, The Economic Structure of Tort Law, Harvard University Press, Cambridge, 1987.

Mattiacci, Giuseppe Dari, and Francesco Parisi, "The Cost of Delegated Control: Vicarious Liability, Secondary Liability, and Mandatory Insurance," George Mason University School of Law, Law \& Economics Working Paper Series, 02-27, 2002.

McKean, Roland N. "Products Liability: Implications of Some Changing Property Rights," Quarterly Journal of Economics, Vol. 84(4), 1970, pp. 611-26.

Note, "Absolute Liability for Ammunition," Harvard Law Review, Vol. 108, pp. 1679-1696, 1995.

Note, "Manufacturers' Strict Liability for Handgun Injuries: An Economic Analysis," Georgetown Law Journal, Vol. 73, pp. 1437- 1462, 1995.

Polinsky, A. Mitchell, "Strict Liability vs. Negligence in a Market Setting," American Economic Review, Vol. 70 (2), 1980, pp. 363-367.

Polinsky, A. Mitchell, and William P. Rogerson, "Products Liability, Consumer Misperceptions, and Market Power," Bell Journal of Economics, Vol. 14 (2), 1983, pp. 581-89.

Riley, John G., "Informational Equilibrium," Econometrica, Vol. 47(2), 1979, pp. 331-359.

Riley, John G., "Silver Signals: Twenty Five Years of Signaling and Screening," Journal of Economic Literature, Vol. 39(2), 2001, pp. 432-478.

Rothschild, Michael, and Joseph Stiglitz, "Equilibrium in Competitive Insurance Markets," Quarterly Journal of Economics, Vo. 90, 1976, pp. 629-650.

Shavell, Steven, "Strict Liability versus Negligence," Journal of Legal Studies, Vol. 9(1), 1980, pp. 1-25.

Shavell, Steven. "The Judgment Proof Problem," International Review of Law and Economics, Vol. 6(1), 1986, pp. 45-58.

Sykes, Alan O., "Vicarious Liability." In Peter Newman, ed., The New Palgrave Dictionary of Economics and the Law, Macmillan Reference Limited, 1998.

Spence, A. M., "Consumer Misperceptions, Product Failure, and Producer Liability," Review of Economic Studies, Vol. 44 (3), 1977, pp. 561-572.

Wilson, Charles A., "A Model of Insurance Markets with Incomplete Information," Journal of Economic Theory, Vol. 16, 1977, pp. 167-207. 


\section{Appendix}

Proof of Propositions 1 and 2: As a benchmark, suppose a social planner chooses $x, q$, and $\delta^{c}$. The consumer chooses $y$ to minimize his expected costs: $\pi(x, y) \delta^{c}+y$. Our earlier assumptions guarantee that this $\mathrm{y}$ is positive and unique. Implicitly, $y=f\left(x, \delta^{c}\right)$ where $f_{\delta}\left(x, \delta^{c}\right)>0$. Holding $x$ fixed, if $\delta^{c}<d\left(\delta^{c}>d\right)$ then the consumer under-invests (over-invests) relative to what a social planner would do. The most efficient liability rule is $\delta^{c}=\min \{d, w\}$. Substituting into (1), the social planner would choose $x$ and $q$ to maximize:

$$
\int_{0}^{q}[P(z)-\pi(x, f(x, \min \{d, w\})) d-x-f(x, \min \{d, w\})] d z .
$$

The benchmark solution satisfies

$$
\begin{aligned}
& x^{* *}=\underset{x}{\arg \min } \pi(x, f(x, \min \{d, w\})) d+x+f(x, \min \{d, w\}), \\
& y^{* *}=f\left(x^{* *}, \min \{d, w\}\right), \\
& P\left(q^{* *}\right)=\pi\left(x^{* *}, y^{* *}\right) d+x^{* *}+y^{* *} .
\end{aligned}
$$

Claim: The competitive equilibrium is the benchmark, $\{\hat{x}, \hat{y}, \hat{q}\}=\left\{x^{* *}, y^{* *}, q^{* *}\right\}$, if and only if $\delta^{c}=\min \{d, w\}$ and $\delta^{m}=d-\min \{d, w\}$

Proof of claim: Inequality (5) clearly binds, $p=x+\pi(x, y) \delta^{m}$. Substituting this and $y=f\left(x, \delta^{c}\right)$ into (2) and (4) gives an equivalent program:

$$
\begin{aligned}
\underset{x}{\operatorname{Max}} \int_{0}^{q}\left[P(z)-\pi\left(x, f\left(x, \delta^{c}\right)\right)\left(\delta^{m}+\delta^{c}\right)-x-f\left(x, \delta^{c}\right)\right] d z \\
\text { s.t. } \quad P(q)=\pi\left(x, f\left(x, \delta^{c}\right)\right)\left(\delta^{c}+\delta^{m}\right)+x+f\left(x, \delta^{c}\right)
\end{aligned}
$$

Using the envelope theorem we find the competitive equilibrium $\{\hat{x}, \hat{y}, \hat{q}\}$ satisfies

$$
\begin{aligned}
& \hat{x}=\underset{x}{\arg \min } \pi\left(x, f\left(x, \delta^{c}\right)\right)\left(\delta^{c}+\delta^{m}\right)+x+f\left(x, \delta^{c}\right), \\
& \hat{y}=f\left(\hat{x}, \delta^{c}\right), \\
& P(\hat{q})=\pi(\hat{x}, \hat{y})\left(\delta^{c}+\delta^{m}\right)+\hat{x}+\hat{y} .
\end{aligned}
$$


$\{\hat{x}, \hat{y}, \hat{q}\}=\left\{x^{* *}, y^{* *}, q^{* * *}\right\}$ with residual-manufacturer liability. With $\delta^{c}=d$ and $\delta^{m}=0$, $\{\hat{x}, \hat{y}, \hat{q}\}=\left\{x^{*}, y^{*}, q^{*}\right\}$.

Proof of Proposition 3: $\quad \frac{\Delta_{H} D_{H}(p)+\Delta_{L} D_{L}(p)}{D_{H}(p)+D_{L}(p)}>\frac{\Delta_{H} D_{H}^{\prime}(p)+\Delta_{L} D_{L}^{\prime}(p)}{D_{H}^{\prime}(p)+D_{L}^{\prime}(p)}$ if and only if $D_{H}(p) D_{L}^{\prime}(p)<D_{H}^{\prime}(p) D_{L}(p)$. Dividing both sides by $D_{H}(p) D_{L}(p)$ and multiplying by $-p$ shows this is equivalent to $\varepsilon_{H}(p)<\varepsilon_{L}(p)$. This orders the prices under residual-manufacturer liability and the benchmark. The order of the quantities follows.

Proof of Proposition 4: With consumer-only liability, the price $p^{C}=0$. When $\varepsilon_{H}(p)>\varepsilon_{L}(p)$ then $p^{*}>p^{R}>p^{C}$; when $\varepsilon_{H}(p)<\varepsilon_{L}(p)$ then $p^{R}>p^{*}>p^{C}$. The result follows from the quasiconcavity of social welfare.

Proof of Proposition 5: Holding the average harm, $p^{R}$, fixed in equation (7) we may define $\Delta_{L}$ as a function of $\Delta_{H}: \Delta_{L}\left(\Delta_{H}\right)$ where $\frac{d \Delta_{L}\left(\Delta_{H}\right)}{d \Delta_{H}}=-\frac{D_{H}\left(p^{R}\right)}{D_{L}\left(p^{R}\right)}$. Social welfare with consumeronly liability $\left(p^{c}=0\right)$ may be written $\int_{0}^{D_{H}(0)}\left[P_{H}(z)-\Delta_{H}\right] d z+\int_{0}^{D_{L}(0)}\left[P_{L}(z)-\Delta_{L}\left(\Delta_{H}\right)\right] d z$.

Differentiating with respect to $\Delta_{H}$ and substituting the derivative of $\Delta_{L}\left(\Delta_{H}\right)$ gives

$$
-D_{H}(0)-\left(\frac{d \Delta_{L}\left(\Delta_{H}\right)}{d \Delta_{H}}\right) D_{L}(0)=-D_{H}(0)+\left(\frac{D_{H}\left(p^{R}\right)}{D_{L}\left(p^{R}\right)}\right) D_{L}(0) .
$$

This is positive if $D_{H}(p) / D_{L}(p)$ is increasing in price or equivalently $\varepsilon_{H}(p)<\varepsilon_{L}(p)$.

Proof of Proposition 6: Suppose perfect price discrimination is possible. It follows from Proposition 1 that the solvent consumers will be efficiently supplied, $x_{1}=x^{*}$ and $y_{1}=y^{*}$. For the insolvent consumers the market outcome is $x_{0}=y_{0}=0$. The market price is $p_{1}=x^{*}$ for the solvent consumers and $p_{1}=0$ for the insolvent consumers. Incentive compatibility is satisfied so this is also the equilibrium with incomplete information. 
Proof of Lemma 7: For the solvent consumers, residual-manufacturer liability is equivalent to consumer-only liability so by Proposition 1 they are supplied efficiently. From the proof of Propositions 1 and 2, the insolvent consumers take zero precautions $y_{0}=0$ and manufacturer precautions satisfy $x_{0}=\arg \min \pi(x, 0) d+x$. Therefore $x_{0}=x^{*}$ and $P\left(q_{0}\right)=\pi\left(x^{*}, 0\right) d+x^{*}$, the efficient levels.

Proof of Proposition 8: Suppose a pooling equilibrium, $\{\hat{p}, \hat{x}\}$, does exist and let $\hat{\theta}$ be the proportion of insolvent types. Zero-profits implies $\hat{p}=\hat{x}+\hat{\theta} \pi(\hat{x}, 0) d$. Consider a deviation to $\{\tilde{p}, \tilde{x}\}=\{\hat{p}+\rho, \hat{x}+\varepsilon\}$. The insolvent consumers prefer $\{\hat{p}, \hat{x}\}$ to $\{\tilde{p}, \tilde{x}\}$ and the solvent consumer prefers $\{\tilde{p}, \tilde{x}\}$ to $\{\hat{p}, \hat{x}\}$ when $0<\rho<\left[\pi\left(\hat{x}, y^{*}\right)-\pi\left(\hat{x}+\varepsilon, y^{*}\right)\right] d$. The deviator receives positive profits when $\tilde{p}>\tilde{x}$ or $\rho>\hat{x}+\varepsilon-\hat{p}$. Substituting for $\hat{p}$ gives $\rho>\varepsilon-\hat{\theta} \pi(\hat{x}, 0) d$. When $\varepsilon$ is sufficiently small then this condition is satisfied for any $\rho>0$.

Claim: In any separating equilibrium, $\left\{p_{1}^{R}, x_{1}^{R}\right\} \quad$ and $\quad\left\{p_{0}^{R}, x_{0}^{R}\right\}, \quad p_{1}^{R}=x_{1}^{R} \quad$ and $p_{0}^{R}=x_{0}^{R}+\pi\left(x_{0}^{R}, 0\right) d$.

Proof of claim: Suppose $p_{0}^{R}>x_{0}^{R}+\pi\left(x_{0}^{R}, 0\right) d$. By deviating to $\left\{p_{0}^{R}-\rho, x_{0}^{R}\right\}$ a manufacturer could profitably capture the type 0 market. (If he attracts the solvent consumers too, all the better.) Suppose that $p_{1}^{R}>x_{1}^{R}$. The incentive compatibility constraint for the insolvent consumer holds that $p_{0}^{R} \leq p_{1}^{R}$. By deviating to a slightly higher safety level, $\left\{p_{1}^{R}, x_{1}^{R}+\varepsilon\right\}$, a manufacturer could profitably capture the entire type 1 market.

Claim: $x_{0}^{R}=x^{*}$.

Proof of claim: $\left\{p_{0}, x_{0}\right\}=\left\{x^{*}+\pi\left(x^{*}, 0\right) d, x^{*}\right\}$ is the outcome with perfect price discrimination. If $\left\{p_{0}^{R}, x_{0}^{R}\right\}$ did not have this form, then a deviator would steal the entire type 0 market $\left\{p_{0}+\rho, x_{0}\right\}$ (if the type 1 consumers accept, too, all the better for the deviator.) 
Claim: $x_{1}^{R}=x^{*}+\pi\left(x^{*}, 0\right) d$.

Proof of claim: Given the two claims proved earlier, the IC constraints for the two types are:

$\left(\mathrm{IC}_{0}\right): \quad x^{*}+\pi\left(x^{*}, 0\right) d \leq x_{1}^{R}$,

$\left(\mathrm{IC}_{1}\right): \quad x_{1}^{R}+\pi\left(x_{1}^{R}, y^{*}\right) d \leq x^{*}+\pi\left(x^{*}, 0\right) d+\pi\left(x^{*}, y^{*}\right) d$.

$\left(\mathrm{IC}_{0}\right)$ implies that $x_{1}^{R}>x^{*}$. If $\left(\mathrm{IC}_{0}\right)$ were slack, then the type 1 consumers could be made better off by lowering $x_{1}^{R}$ closer to $x^{*}$. If $\left(\mathrm{IC}_{0}\right)$ binds then $\left(\mathrm{IC}_{1}\right)$ is slack.

Claim: When $\theta$ is sufficiently large there is no unilateral deviation that both types would prefer. Proof of claim: Suppose $\{\tilde{p}, \tilde{x}\}$ is preferred by both types and let $\tilde{\theta}$ be the proportion of insolvent types at that deviation. Positive profits for the deviator implies $\tilde{p} \geq \tilde{x}+\tilde{\theta} \pi(\tilde{x}, 0) d$. The deviation is preferred by the insolvent consumers when $\tilde{p} \leq x^{*}+\pi\left(x^{*}, 0\right) d=p_{0}^{R}$. Taken together, we have $\tilde{x}+\tilde{\theta} \pi(\tilde{x}, 0) d \leq x^{*}+\pi\left(x^{*}, 0\right) d$. When $\theta=1$ then $\tilde{\theta}=1$ as well, so this inequality is only satisfied when $\{\tilde{p}, \tilde{x}\}=\left\{p_{0}^{R}, x_{0}^{R}\right\}$. We have already seen that the type 1 consumers would prefer $\left\{p_{1}^{R}, x_{1}^{R}\right\}$, a contradiction. Continuity completes the proof.

Proof of Proposition 9: Let $S_{i}^{j}$ be the social welfare associated with liability regime $j$ for a representative consumer of type $i$. Consumer-only liability is preferred if $\theta S_{0}^{C}+(1-\theta) S_{1}^{C}>$ $\theta S_{0}^{R}+(1-\theta) S_{1}^{R}$, or $(1-\theta)\left(S_{1}^{C}-S_{1}^{R}\right)>\theta\left(S_{0}^{R}-S_{0}^{C}\right)$. Note that $S_{1}^{C}>S_{1}^{R}$ because solvent consumers are served efficiently under consumer-only liability (Proposition 6) but not under residual-manufacturer liability (Proposition 8 ). $S_{0}^{R}>S_{0}^{C}$ because manufacturers supply efficient safety features to the insolvent consumers under residual-manufacturer liability and the market quantity is optimal. The result follows. 